\title{
Adaptation to Climate Change of Wheat Growing in South Australia: Analysis of Management and Breeding Strategies
}

\author{
*Qunying Luo ${ }^{1}$, William Bellotti ${ }^{2}$, Martin Williams ${ }^{1}$ and Enli Wang ${ }^{3}$ \\ ${ }^{1}$ Department of Geographical and Environmental Studies, University of Adelaide, \\ South Australia, 5005, Australia \\ ${ }^{2}$ School of Agriculture \& Wine, University of Adelaide, \\ South Australia, 5371, Australia \\ ${ }^{3}$ CSIRO Land and Water, GPO Box 1666, Canberra, ACT2601, Australia
}

\begin{abstract}
Evaluation of adaptive management options is very crucial for successfully dealing with negative climate change impacts. Research objectives of this study were (1) to determine the proper $\mathrm{N}$ application rate for current practice, (2) to select a range of synthetic wheat (Triticum aestivum L.) cultivars to expand the existing wheat cultivar pool for adaptation purpose, (3) to quantify the potential impacts of climate change on wheat grain yield and (4) to evaluate the effectiveness of three common management options such as early sowing, changing $\mathrm{N}$ application rate and use of different wheat cultivars derived in (2) and given in the APSIM-Wheat model package in dealing with the projected negative impacts for Keith, South Australia. The APSIM-Wheat model was used to achieve these objectives. It was found that $75 \mathrm{~kg}$ ha- $1 \mathrm{~N}$ application at sowing for current situation is appropriate for the study location. This provided a non-limiting $\mathrm{N}$ supply condition for climate change impact and adaptation evaluation. Negative impacts of climate change on wheat grain yield were projected under both high (-15\%) and low (-10\%) plant available water capacity conditions. Neither changes in $\mathrm{N}$ application level nor in wheat cultivar alone nor their synergistic effects could offset the negative climate change impact. It was found that early sowing is an effective adaptation strategy when initial
\end{abstract}

\footnotetext{
${ }^{*}$ Corresponding author current organisation and contacts

NSW Department of Primary Industries

Postal address: PO BOX 100, Beecroft, NSW, 2119 Australia

Email: qunying.luo@2003.adelaide.edu.au (perpetual email), qunying.luo@dpi.nsw.gov.au

Phone: 61298720117 Fax: 61298716941
} 
soil water was reset at $25 \mathrm{~mm}$ at sowing but this may be hard to realise especially since a drier environment is projected.

Key words: wheat grain yield, climate change, impact assessment, adaptation evaluation, early sowing, cultivars choices, $N$ application level

\section{Introduction}

Impact and adaptation are key components of climate change risk assessment. While the former issue has been extensively studied the latter still needs to be comprehensively investigated. Compared with the large number of impact assessment studies, adaptation evaluation is seldom adequately assessed, even though a few studies have considered these two issues together by using process-oriented crop models (Wang et al, 1992; Qureshi and Iglesias, 1994; Seino, 1995; Brklacich and Stewart, 1995; Baethgen and Magrin; 1995; Delécolle et al., 1995; Bayasgalan et al., 1996; Rosenzweig and Iglesias, 1998; Howden et al., 1999; Reyenga et al., 1999a, Torriani et al., 2007). However, most climate change risk assessment studies so far end with impact assessment (some examples are Aggarwal and Sinha, 1993; Barry and Geng, 1995; Tubiello et al., 1995; Pilifosova et al., 1996; Karim et al., 1996; Reyenga et al., 1999b; Luo et al., 2003; 2005a, b; Van Ittersum et al., 2003). To some extent, the role of impact assessment is to set the scene for adaptation evaluation. Without addressing adaptation, climate change risk assessment is incomplete. The ultimate purpose of climate change risk assessment is to identify adaptation strategies and evaluate their effectiveness in counteracting the negative climate change impacts for the sustainable development of a specific sector/region. Several factors have impeded the balanced development of adaptation studies compared with impact assessment. One concerns the considerable uncertainties in regional climate change 
risk assessment. The other concerns the difficulty in quantifying certain management options.

A few studies dealt with adaptation issues in Australia. Wang et al. (1992) assessed the interactive impacts of increase in $\mathrm{CO}_{2}$ concentration and in temperature on wheat yields in Victoria. They suggested that doubling of $\mathrm{pCO}_{2}$ to $700 \mathrm{ppm}$ would increase yields by $28 \%$ to $43 \%$, but that simultaneous increases in temperature of $3^{\circ} \mathrm{C}$ would decrease yields by $25 \%$ to $60 \%$ using current cultivars or cause a substantial increase in yield if a late-maturing variety from Queensland was used. Howden et al. (1999) quantified the potential impacts of climate change on wheat production and explored the benefit of early sowing at nine wheat production areas in Australia for the period centred on 2070 based on the CSIRO (1996) climate change scenarios, with atmospheric $\mathrm{CO}_{2}$ set at 700ppm. Reyenga et al. (1999a) assessed the possible impacts of climate change and increased atmospheric $\mathrm{pCO}_{2}$ on wheat production in southeast Queensland by applying the same source of climate change scenarios as Howden et al. (1999). Management options such as nitrogen application and cultivar maturities were evaluated in dealing with climate change risk. It was found that $\mathrm{N}$ application enhanced wheat yield across all scenarios considered and that late maturity and early maturity varieties generally have lower wheat yields than standard varieties.

Similar studies were conducted in Europe. Torriani et al. (2007) quantified the potential impacts of changes in mean climate and in climate variability on crop yields in Switzerland. Increasing growing degree days (equivalent to the use of later maturity cultivar) and later sowing were evaluated in adapting to negative climate change impacts. In contrast to above mentioned process-oriented modelling approach, Reidsma et al. (2007) addressed adaptive capacity issue in Europe by adopting a statistical modelling approach. 
This study aims to quantify the potential impacts of climate change on wheat grain yield and to evaluate the effectiveness of a range of management options in dealing with climate change risks in South Australia (SA) by coupling the outputs of a higher spatial and temporal resolution climate model with a wheat model. To achieve this aim, two ancillary studies were carried out before the core study. One is a sensitivity study of $\mathrm{N}$ application rate at sowing. The purpose of this ancillary study is to determine an appropriate $\mathrm{N}$ application rate to avoid haying-off and to achieve a nonlimiting $\mathrm{N}$ supply condition for climate change impact and adaptation studies. The other is the identification of synthetic cultivars through changes in vernalisation and photoperiod coefficients used by the wheat model to expand the cultivar pool for adaptation evaluation in addition to existing wheat cultivars included in the APSIMWheat package.

\section{Methodologies}

\subsection{Study site}

This study focused on Keith, which is located in the southeast of South Australia and is one of the major wheat production areas in this state. This location receives midhigh annual rainfall (468mm) with average growing season (May-Oct. inclusive) rainfall of 315mm under a Mediterranean climate.

\subsection{Method}

The Agricultural Production System sIMulator (APSIM)-Wheat model (version 4.1) was used in the two ancillary studies and the core study (climate change impact assessment and adaptation evaluation). The APSIM-Wheat module has been described in detail elsewhere (Keating et al., 2003; Luo, 2003). The performance of 
APSIM-Wheat in the Australian environment (Keating et al., 2003) and in the South Australian environment (Luo, 2003; Yunusa et al., 2004) has been evaluated. The physiological effects of increased atmospheric $\mathrm{CO}_{2}$ on wheat production were included in the simulations. Modifications have been made to the Wheat module through changes to radiation use efficiency (RUE), transpiration efficiency (TE) and to critical nitrogen concentration (CRC) based on experimental data (Reyenga et al., 1999a; Luo, 2003).

\subsection{Climate and soil data}

\section{Climate data}

Historical daily climate data (solar radiation, maximum temperature, minimum temperature and rainfall) for the period of 1906-2005 for Keith were gathered from SILO patched point dataset (PPD) at http://www.nrw.qld.gov.au/silo/ppd. This period of historical climate data was directly used by the APSIM-Wheat model in the two ancillary studies. Historical climate data for the period of 1958-2005 were used by a stochastic weather generator (LARS-WG) to produce 100-year baseline climate and climate changes scenarios for the quantification of climate change impacts and adaptive options. The rationale for this procedure is to produce climate change scenarios with both changes in mean climate and in climate variability considered, which is an important issue in the field of climate change impact assessment. Semenov et al. (1998), Semenov (2007, 2008) and Qian et al. (2004) applied and evaluated the performance of LARS-WG across a wide range of environments in the world. Figure 1 details the usage of historical climate data in this study.

Figure 1 
To generate future climate change scenarios, the outputs of the CSIRO conformal cubic atmospheric model (C-CAM) for 2080 were used. C-CAM is a regional climate model with spatial resolution of $50 \mathrm{~km}$ by $50 \mathrm{~km}$. The performance of the C-CAM in South Australia can be found in Suppiah et al. (2006). Table 1 presents climate change information including changes in mean climate (mean rainfall, mean temperature, mean solar radiation) and changes in climate variability (wet spells, dry spells and temperature variability) for the growing season at Keith.

\section{Table 1}

\section{Soil data}

A sandy loam soil (Calcisol soil group, FAO, 1991; Calcarosol order, Australian Soil Classification, McKenzie et al., 2004) was used in this study. Two levels of soil depth were considered in this study: deeper soil and shallower soil. Table 2 details soil water and nitrogen parameters for each layer used by the APSIM-Wheat Model. The deeper soil has a total of 161mm plant available water capacity (PAWC) and a total of $112 \mathrm{~kg}$ ha-1 NO3-N and a total of $3832 \mathrm{~kg}$ ha- 1 organic $\mathrm{N}$ up to $130 \mathrm{~cm}$ depth, while the shallower soil has a PAWC of $85 \mathrm{~mm}$ and NO3-N of $80.5 \mathrm{~kg}$ ha-1 and $2797 \mathrm{~kg}$ ha- 1 organic $\mathrm{N}$ in total to a depth of $70 \mathrm{~cm}$. The ratio between carbon and nitrogen was set to 80. For simplicity, we refer to the two levels of soil depth as high and low PAWC thereafter. It should be noted that the low PAWC condition was only used in the core study rather than in the two ancillary studies.

Table 2

\subsection{Model settings and simulation experimental design}

The cultivar Chara (PIRSA, 2001) was used in this simulation study. Chara is a midlate maturing cultivar and is common in SA. 
Wheat can be sown at any time between April and August depending on the opening rain. Figure 2 shows the distribution of sowing time based on the 100-year historical daily climate data. It can be seen that the sowing window at this location is quite wide spanning from April to August due to the large inter-annual variability of starting rain. Median sowing time lies between the middle and end of May. Based on this information we considered a fixed sowing time: 27 May in this study. Sowing depth is $3 \mathrm{~cm}$. The purpose of using fixed sowing rather than dynamic sowing (sowing rule) is to exclude the interactive effects between sowing time and climate change so that a clearer impact message can be obtained and adaptation strategies can be identified.

Figure 2

Soil nitrogen and residue were reset to initial condition at sowing. Soil water was reset to $25 \mathrm{~mm}$ at sowing at a depth of available soil water from the top of the profile. This is equivalent to irrigation to ensure reasonable emergence rate for tracing/detecting the footprint of the impact of climate change. Other information at sowing time such as amount of nitrogen application, residue, and plant density is shown in Table 3.

\section{Table 3}

In addition to the above general model setting and simulation experimental design, individual studies have their own specific simulation designs as detailed below:

\subsubsection{Ancillary study 1: Identification of appropriate nitrogen application level}

To exclude the interactive effects of $\mathrm{N}$ application rate and climate change, a nonlimiting $\mathrm{N}$ supply status is normally maintained for climate change risk assessment. A sensitivity study between grain yield and $\mathrm{N}$ application rates was conducted to achieve the non-limiting $\mathrm{N}$ supply condition based on 100 -year historical climate data. 
Nitrogen is normally applied before or at seeding, around mid-tillering and preflowering to enhance profit. In this study we considered 5 levels (0, 50, 100, 150, 200 kg ha-1) of NO3-N application at sowing. These levels of $\mathrm{N}$ application override the $\mathrm{N}$ application described in section 2.4 and in Table 3.

\subsubsection{Ancillary study 2: derivation of synthetic cultivars}

Cultivar maturity is described in the APSIM-Wheat model by two factors: photoperiod and vernalisation sensitivity. Chara has a vernalisation sensitivity coefficient of 2.8, and a photoperiod sensitivity coefficient of 3.0. In order to expand the existing cultivar pool, we increased and decreased these two values individually at an interval of 0.5 within the ranges of these two coefficients available in the APSIMWheat model package. This resulted in five levels of photoperiod and vernalisation coefficient including Chara itself (Table 4). The bold figures in Table 4 are the coefficients for Chara. The others were derived from these two figures as described above. As a result there are 24 combinations of photoperiod and vernalisation coefficients which were used by the APSIM-Wheat model to identify earlier and later maturity cultivars and applied to the following adaptation study.

Table 4

\subsubsection{Climate change risk assessment}

In addition to the general model setting and simulation experimental design as described in section 2.4, some additional settings apply to climate change risk assessment. The $\mathrm{N}$ application rate of $75 \mathrm{~kg}$ ha- 1 was used based on the results of section 2.4.1. The atmospheric $\mathrm{CO}_{2}$ concentration for 2080 was set to $682 \mathrm{ppm}$ (A2 emission scenarios under the special report on emission scenarios) in the APSIM- 
Wheat model. A transient increase in atmospheric $\mathrm{CO}_{2}$ concentration was implemented in this study.

In regard to adaptation, we considered a range of common management options

- Earlier sowing (crop sown on the 13th of May which is two weeks earlier than the baseline sowing 27 May). It is widely recognised that there is a drop in grain yield due to late sowing in Australian wheat cropping systems.

- Changing $\mathrm{N}$ application rate $(50 \mathrm{~kg}$ ha-1 lower and higher than baseline application rate: $75 \mathrm{~kg}$ ha-1). On the one hand, wheat crops may need a higher $\mathrm{N}$ supply to maintain the current $\mathrm{C}: \mathrm{N}$ ratio under higher $\mathrm{pCO}_{2}$ condition. On the other hand, a lower $\mathrm{N}$ application rate may be needed under a warmer and drier environment. We increased and decreased the $\mathrm{N}$ application rate around the baseline $\mathrm{N}$ application level.

- Changing wheat cultivars derived from Chara mentioned in section 2.4.2 and given in the APSIM-Wheat package including earlier and later maturity (Table 5). Choice of a late maturity cultivar may be effective in counteracting the negative effects of warmer environment on grain yield due to the reduction in crop life cycle especially the development stages. However, earlier maturity cultivars may be needed to match future drier conditions. These need to be tested by adopting a systematic approach.

Table 5

\section{Results}

\subsection{Ancillary studies}

\section{Yield response to nitrogen application levels}

Grain yield of $c v$ Chara responded to different levels of $\mathrm{N}$ application up to rate of 100kg ha-1, after which no significant response could be detected under the soil 
nitrogen condition considered in this study at the sowing time of 27 May (Figure 3). It seems that $75 \mathrm{~kg}$ ha-1 $\mathrm{N}$ application at the study location (Keith) is appropriate according to the response of grain yield to nitrogen application levels at this sowing time which falls in the most likely sowing window over the period 1906-2005.

Figure 3

\section{Synthetic cultivars with earlier and later maturity characteristics}

Table 5 shows the difference in median flowering time between synthetic cultivars and Chara based on 100-year historical daily climate data for sowing time 27 May at Keith. It can be seen that median flowering time varies from -14 (earlier) to +19 (later) days across the 24 combinations of vernalisation and photoperiod coefficient discussed earlier.

\section{Table 6}

\subsection{Climate change impacts}

Negative impacts of future climate change on wheat (Chara) yields were projected under both high and low PAWC conditions if adaptation options were not taken into account (Figure 4). Under high PAWC, the simulated baseline wheat yield is $3375 \mathrm{~kg}$ ha- 1 while this value dropped to $2879 \mathrm{~kg}$ ha- 1 under the climate change scenario (2080), which is about a 15\% decline. Negative impacts were also projected under low PAWC. Wheat yields of $3255 \mathrm{~kg}$ ha-1 and $2874 \mathrm{~kg}$ ha-1 were simulated for baseline and climate change scenario respectively. This is about a $12 \%$ decrease under the low PAWC condition. Statistical tests (t-test) were conducted to examine if significant difference exists between baseline yields and 2080 yields under high and low PAWC. Statistical tests show that significant difference exists in wheat yield 
between baseline and 2080 with p-value $=0.0003$ for high PAWC and p-value $=0.0035$ for low PAWC.

Figure 4

\subsection{Management options in dealing with projected negative climate change impacts}

\subsubsection{Earlier sowing}

By adopting an earlier sowing strategy (crop sown $13^{\text {th }}$ of May), wheat grain yields of 3471kg ha-1 under high PAWC and 3225kg ha-1 under low PAWC were simulated for 2080 which exceeded their corresponding baseline yield (3372kg ha-1 under high PAWC and 3208kg ha-1 under low PAWC, Figure 4).

\subsubsection{Grain yield response to changes in $\mathrm{N}$ application rate and in cultivar choice}

Figure 5 shows percentage changes of wheat grain yields in 2080 compared to baseline wheat yields across the ranges of vernalisation and photoperiod sensitivities and $\mathrm{N}$ application rates under the two soil water conditions (high and low PAWC) considered in this study. It can be seen that whether changing $\mathrm{N}$ application rate or wheat cultivar, wheat grain yield in 2080 can not be maintained at the current production level.

Under high PAWC, wheat yield in 2080 decreased from 28\% to 35\% when 25kg ha-1 of $\mathrm{N}$ was applied. Decreases in wheat grain yield for 2080 range from $12 \%$ to $30 \%$ for 75kg ha-1 (baseline) and from $11 \%$ to $28 \%$ for $125 \mathrm{~kg}$ ha-1 $\mathrm{N}$ application levels. Little increase in wheat yield can be achieved by increasing $\mathrm{N}$ application rate beyond 75kg ha-1. 
Under low PAWC, wheat grain yield decreased from $17 \%$ to $32 \%$ when $25 \mathrm{~kg}$ ha- $1 \mathrm{~N}$ was applied. Decreases in wheat grain yield range from $10 \%$ to $27 \%$ for baseline (75ka/ha) and from $10 \%$ to $25 \%$ for $125 \mathrm{~kg}$ ha- $1 \mathrm{~N}$ application rates. Once again, these two yield change ranges are very close to each other with the latter two $\mathrm{N}$ application rates.

Even though wheat grain yield in 2080 could not be maintained at current production level when using other cultivars, wheat yields decrease less when some mid maturing cultivars (earlier than the mid-late maturity cultivar-Chara) from the APSIM-Wheat package such as annuello, frame, yitpi, mitre and yallario and some synthetic cultivars such as vop2, v1p2, v2p0 and $v 2 p 1$ were used under non-limiting $\mathrm{N}$ supply (75 and 125kg ha-1 N application) and high PAWC condition. Yields decrease less when the current cultivar Chara was used under non-limiting N supply and low PAWC.

Figure 5

\section{Discussion}

This study quantified the potential impacts of climate change on wheat production for 2080 and evaluated the effectiveness of some common management options (early sowing, changing $\mathrm{N}$ application levels and use of different cultivars). It seems that early sowing (13 May: 2 wks earlier than baseline sowing 27 May) is an effective adaptation strategy in dealing with the adverse effects of climate change (Figure 4). This is in line with the study of Howden et al. (1999a). However, it should be noted that initial soil water was reset at $25 \mathrm{~mm}$ in this study to ensure a reasonable emergence rate. A drier condition for the growing season was projected by the regional climate models used in this study which implies less chance of early seasonal break (early sowing) under changed climate. In other words, the beneficial effects of 
early sowing may not be realised for rainfed wheat production systems under future climate conditions. This suggests that other possible adaptation options such as irrigation, itself limited by water availability and accessibility, may be needed for sustainable development of wheat production for the region under study.

Wang et al. (1992) found that substantial yield increase could be achieved if a latematuring variety from Queensland was used in wheat production systems at Horsham. Similar results were found in Torriani et al. (2007). However the beneficial effects of adopting late maturity cultivars were not found in Reyenga et al. (1999a) and in our study. There are a couple of reasons for this difference. Changes in rainfall were not considered in Wang et al. (1992). Increase in rainfall was projected in the study of Torriani et al. (2007). Under a drier environment projected by the regional climate model in our study, earlier maturity cultivars may be more favourable than later maturity cultivars especially under high PAWC.

Other management options such as soil water conservation measures (i.e. stubble retention, and zero and minimal tillage) were not considered in this study. Their effectiveness in counteracting projected negative climate change impacts needs to be quantified in the future. Changing $\mathrm{N}$ application time such as splitting $\mathrm{N}$ application at key crop phenological stages such as tillering and heading may enhance grain yield. This and other management options need to be further investigated in the near future when addressing adaptation issues. It is important to note that this study is based on the outputs of one regional climate model. It is widely recognised that there are uncertainties between different climate models. To obtain a more comprehensive picture of climate change impacts and effectiveness of adaptation options, outputs from multiple climate models should be applied in future climate change risk assessment. 


\section{Conclusions}

The APSIM-wheat model was used in this study to assess climate change risk. It was found that both changes in $\mathrm{N}$ application level and in wheat cultivars alone and simultaneous changes of these two factors could not bring 2080 wheat yields back to the current wheat production levels for the two soil water conditions considered due to the increase in the frequency of drought events and limited genetic resources explored in this study. This has implications for future crop management and plant breeding. Soil water conservation practices and improvement in water use efficiency should be encouraged in future crop management. Cultivars with heat/drought tolerant genetic characteristics should be developed.

Limitations of this study arise from the use of fixed sowing rather than dynamic sowing due to the consideration of investigating the effects of sowing time on wheat production and limited choices in the APSIM-Wheat model for adjusting genetic coefficient parameters to generate more diversified synthetic cultivars for adaptation evaluation. To enhance the capacity of climate change risk assessment, crop models need to be improved.

\section{Acknowledgement}

We thank Dr Victor Sadras (South Australia Research and Development Institute) and Neil Huth (Sustainable Ecosystems, CSIRO) for their useful suggestions in deriving synthetic wheat cultivars. We thank Peter Devoil, Queensland Department of Primary Industry for his technical support in extracting climate change information from NetCDF format to common/usable format. This project was supported by Australian Research Council Linkage Grant LP0348864. 


\section{References}

Aggarwal, P.K., Sinha, S.K., 1993. Effect of probable increase in carbon dioxide and temperature on wheat yields in India. Journal of Agricultural Meteorology. 48 (5), 811-814.

Baethgen, W.E., Magrin, G.O., 1995. Assessing the impacts of climate change on winter crop production in Uruguay and Argentina using crop simulation models. In: Rosenzweig, C., Ritchie, J.T., Jones, J.W. (Eds.), Climate Change and Agriculture: Analysis of Potential International Impacts. ASA Special Publication 59, 207-228.

Barry, T.A., Geng, S., 1995. The effects of climate change on United States rice yields and California wheat yields. In: Rosenzweig, C., Ritchie, J.T., Jones, J.W. (Eds.), Climate Change and Agriculture: Analysis of Potential International Impacts. ASA Special Publication 59, 183-204.

Bayasgalan, Sh., Bolortsetseg, B., Dagvadorj, D., Natsagdorj, L., 1996. The impact of climate change on spring wheat yield in Mongolia and its adaptability. In: Smith, J. B., Bhatti, N., Menzhulin, G., Benioff, R., Budyko, M. I., Campos, M., Jallow, B., Rijsberman, F. (Eds.), Adapting to Climate Change: An International Perspective. Springer-Verlag, New York, USA, pp. 164-173.

Brklacich, M., Stewart, R.B., 1995. Impacts of climate change on wheat yield in the Canadian prairies. In: Rosenzweig, C., Ritchie, J.T., Jones, J.W. (Eds.), Climate Change and Agriculture: Analysis of Potential International Impacts. ASA Special Publication 59, 147-161.

CSIRO, 1996. Climate Change Scenarios for the Australian Region. Climate Impact Group, CSIRO Division of Atmospheric Research, Melbourne, pp. 8. 
Delécolle, R., Ruget, F., Ripoche, D., 1995. Possible effects of climate change on wheat and maize crops in France. In: Rosenzweig, C., Ritchie, J.T., Jones, J.W. (Eds.), Climate Change and Agriculture: Analysis of Potential International Impacts. ASA Special Publication 59, 241-257.

FAO, 1991. World Soil Resources: An Explanatory Note on the FAO World Soil Resources Map at 1: 25000000 scale. World Soil Resources Reports 66. FAO, Rome.

Howden, S.M., Reyenga, P.J., Meinke, H., 1999. Global Change Impacts on Australian Wheat Cropping. Report to the Australian Greenhouse Office.

Karim, Z., Hussain, S.G., Ahmed, M., 1996. Assessing impacts of climatic variations on food-grain production in Bangladesh. Water, Air, and Soil Pollution 92(1-2), 53-62.

Keating, B.A., Carberry, P.S., Hammer, G.L., Probert, M.E., Robertson, M.J., Holzworth, D., Huth, N.I., Hargreaves, J.N.G., Meinke, H., Hochman, Z., McLean, G., Verburg, K., Snow, V., Dimes, J.P., Silburn, M., Wang, E., Brown, S., Bristow, K.L., Asseng. S., Chapman, S., McCown, R.L., Freebairn, D.M., Smith, C.J., 2003. An overview of APSIM, a model designed for farming systems simulation. Eur. J. Agron. 18 (3-4), 267-288.

Luo, Q., 2003. Assessment of the potential impacts of climate change on South Australian wheat production. Unpublished Ph.D. thesis. The University of Adelaide.

Luo, Q., Williams, M.A.J., Bellotti, W., Bryan, B., 2003. Quantitative and visual assessment of climate change impacts on South Australian wheat production. Agricultural Systems 77, 173-186. 
Luo, Q., Bellotti, W.D., Williams, M., Bryan, B., 2005a. Potential impact of climate change on wheat yield in South Australia. Agricultural and Forest Meteorology 132 (3-4), 273-285.

Luo, Q., Bryan, B., Bellotti, W.D., Williams, M., 2005b. Spatial analysis of environmental change impacts on wheat production in Mid-Lower North, South Australia. Climatic Change 72 (1-2), 213-228.

McKenzie, N., Jacquier, D., Isbell, R., Brown, K., 2004. Australian Soils and Landscapes: An Illustrated Compendium. CSIRO Publishing, Melbourne, pp. 416.

Pilifosova, O., Eserkepova, I., Misina, S., 1996. Vulnerability and adaptation assessment for Kazakhstan. In: Smith, J.B., Huq, S., Lenhart, S., Mata, L.J., Nemesova, I., Toure, S. (Eds.), Vulnerability and Adaptation to Climate Change: Interim Results from the U.S. Country Studies Program. Kluwer Academic Publishers, Boston, pp.161-181.

PIRSA, 2001. Crop Harvest Report 2000/2001. Primary Industries and Resources South Australia, Adelaide.

Qian, B.D., Gameda, S., Hayhoe, H., De, Jong R., Bootsma, A., 2004. Comparison of LARS-WG and AAFC-WG stochastic weather generators for diverse Canadian climates. Climate Research 26(3), 175-191.

Qureshi, A., Iglesias, A., 1994. Implications of global climate change for agriculture in Pakistan: impacts on simulated wheat production. In: Rosenzweig, C., Iglesias, A. (Eds.), Implications of Climate Change for International Agriculture: Crop Modelling Study. U.S. EPA, Washington, D. C.

Reidsma, P; Ewert, F., Lansink, A. O., 2007. Analysis of farm performance in Europe under different climate and management conditions to improve understanding of adaptive capacity. Climatic Change 84 (3), 403-422. 
Reyenga, P. J., Howden, S. M., Meinke, H., Mckeon, G. M., 1999a. Modelling global change impacts on wheat cropping in south-east Queesland, Australia. Environmental Modelling and Software 14, 297-306.

Reyenga, P. J., Howden, S. M., Meinke, H., Hall, W. B., 1999b. Global change impacts on wheat production along an environmental gradient in South Australia. Environ. Int. 27, 195-200.

Rosenzweig, C., Iglesias, A., 1998. The use of crop model for international climate impact assessment. In: Tsuji, G.Y., Hoogenboom, G., Thornton, P. K. (Eds.), Understanding Options for Agricultural Production. Dordrecht: Kluwer Academic, the Netherlands.

Seino, H., 1995. Implication of climate change for crop production in Japan. In: Rosenzweig, C., Ritchie, J.T., Jones, J.W. (Eds.), Climate Change and Agriculture: Analysis of Potential International Impacts. ASA Special Publication 59, 293-306.

Semenov, M.A., Brooks, R.J., Barrow, E.M., Richardson, C.W., 1998. Comparison of the WGEN and LARS-WG stochastic weather generators in diverse climates. Climate Research 10, 95-107.

Semenov, M.A., 2007. Development of high resolution UKCIP02-based climate change scenarios in the UK. Agricultural and Forest Meteorology 144, 127-138.

Semenov, M.A., 2008. Simulation of extreme weather events by a stochastic weather generator. Climate Research 35, 203-212.

Suppiah, R., Preston, B., Whetton, P.H., McInnes, K.L., Jones, R.N., Macadam, I., Bathols, J., Kirono, D., 2006. Climate Change under Enhanced Greenhouse Conditions in South Australia. An Updated Report on Assessment of Climate Change, Impacts and Risk Management Strategies Relevant to South Australia. 
Torriani, D.S., Calanca, P., Schmid, S., Beniston, M., Fuhrer, J., 2007. Potential effects of changes in mean climate and climate variability on the yield of winter and spring crops in Switzerland. Climate Research 34, 59-69.

Tubiello, F. N., Rosenzweig, C., Volk, T., 1995. Interactions of $\mathrm{CO}_{2}$, temperature and management practices: simulations with a modified version of CERES-Wheat. Agricultural Systems 49, 135-152.

Van Ittersum, M.K., Howden, S.M., Asseng, S., 2003. Sensitivity of productivity and deep drainage of wheat cropping systems in a Mediterranean environment to changes in $\mathrm{CO}_{2}$, temperature and precipitation. Agric. Ecosys. Env. 97, 255-273.

Wang, Y.P., Handoko, Jr., Rimmington, G.M., 1992. Sensitivity of wheat growth to increases air temperature for different scenarios of ambient $\mathrm{CO}_{2}$ concentration and rainfall in Victoria, Australia-a simulation study. Climate Research 2, 131-149.

Yunusa, I.A.M., Bellotti, W.D., Moore, A.D., Probert, M.E., Baldock, J.A., 2004. An exploratory evaluation of APSIM to simulate growth and yield processes for winter cereals in rotation systems in South Australia. Aust. J. Exp. Agric. 44, 787800. 
Table 1 Anomalies for 2080 and reference climate* at Keith

\begin{tabular}{lllllllllll}
\hline Month & & \multicolumn{3}{c}{ Anomalies } & & \multicolumn{3}{c}{ Reference Climate } \\
& $\mathbf{\Delta}$ Rain & $\begin{array}{l}\Delta \text { Wet } \\
\text { series }\end{array}$ & $\begin{array}{l}\Delta \text { Dry } \\
\text { series }\end{array}$ & $\begin{array}{l}\Delta \text { Tmax } \\
\left({ }^{\mathbf{0}} \mathbf{C}\right)\end{array}$ & $\begin{array}{l}\Delta \text { Tmin } \\
\left({ }^{\mathbf{0}} \mathbf{C}\right)\end{array}$ & $\Delta$ Tsd & $\Delta$ SRAD & $\begin{array}{l}\text { Tmax } \\
\left({ }^{\mathbf{0}} \mathbf{C}\right)\end{array}$ & $\begin{array}{l}\text { Tmin } \\
\left({ }^{\mathbf{0}} \mathbf{C}\right)\end{array}$ & $\begin{array}{l}\text { Rain } \\
(\mathbf{m m})\end{array}$ \\
\hline Jan & 0.88 & 0.86 & 1.17 & 2.30 & 2.00 & 1.07 & 0.99 & 29.8 & 13.1 & 19 \\
Feb & 1.04 & 0.98 & 0.87 & 1.60 & 1.60 & 1.05 & 0.97 & 29.8 & 13.1 & 20 \\
Mar & 1.05 & 0.85 & 1.35 & 0.30 & 0.90 & 0.97 & 0.99 & 26.9 & 11.4 & 21 \\
Apr & 0.83 & 0.83 & 1.20 & 1.60 & 1.30 & 1.02 & 1.03 & 22.5 & 9.2 & 33 \\
May & 0.96 & 0.96 & 1.20 & 2.00 & 1.90 & 0.98 & 1.00 & 18.3 & 7.7 & 53 \\
Jun & 0.92 & 0.80 & 0.91 & 1.90 & 1.80 & 1.03 & 1.04 & 15.5 & 5.9 & 53 \\
Jul & 1.01 & 0.85 & 1.11 & 1.80 & 1.60 & 1.11 & 1.02 & 15.0 & 5.5 & 55 \\
Aug & 0.78 & 0.72 & 1.40 & 1.70 & 1.60 & 1.24 & 0.98 & 16.2 & 5.9 & 58 \\
Sep & 0.90 & 0.85 & 1.17 & 2.30 & 1.30 & 1.21 & 1.03 & 18.6 & 7.0 & 51 \\
Oct & 0.86 & 0.85 & 1.21 & 2.20 & 1.30 & 1.03 & 1.01 & 21.5 & 8.2 & 43 \\
Nov & 0.85 & 0.91 & 1.36 & 2.80 & 1.80 & 1.04 & 1.02 & 24.8 & 9.9 & 32 \\
Dec & 0.83 & 1.06 & 1.02 & 1.60 & 1.30 & 1.06 & 1.01 & 27.6 & 11.8 & 26 \\
\hline
\end{tabular}

*Long time series historical climate data (103 years for rainfall and 62 years for maximum and minimum temperature) were used in deriving reference climate. $(\boldsymbol{\Delta}) \mathrm{Tmax} /(\boldsymbol{\Delta}) \mathrm{Tmin}$ : maximum/minimum temperature; $\boldsymbol{\Delta}$ Tsd: changes in standard deviation of average temperature; $\Delta$ SRAD: changes in solar radiation. For anomalies, $\Delta$ Tmax and $\Delta$ Tmin are absolute change, while others are ratio change. 
Table 2 Soil water and soil nitrogen used in the APSIM-Wheat model

\begin{tabular}{|c|c|c|c|c|}
\hline Depth (mm) & $1115^{\mathrm{a}}(\mathrm{mm} / \mathrm{mm})$ & Dul $^{\mathrm{b}}(\mathrm{mm} / \mathrm{mm})$ & PAWC $^{\mathrm{c}}(\mathrm{mm})$ & NO3-N (kg ha-1) \\
\hline 100 & 0.09 & 0.19 & 10 & 19.56 \\
\hline 250 & 0.1 & 0.21 & 16.5 & 23.51 \\
\hline 420 & 0.11 & 0.24 & 22.1 & 14.92 \\
\hline 700 & 0.11 & 0.24 & 36.4 & 22.51 \\
\hline $900 *$ & 0.18 & 0.3 & 24 & 13.71 \\
\hline $1300 *$ & 0.23 & 0.36 & 52 & 18.06 \\
\hline total & & & $161\left(85^{* *}\right)$ & $112.27\left(80.5^{* *}\right)$ \\
\hline
\end{tabular}

a: lower limit; b: drained upper limit; c: plant available water capacity

*: the last two layers were not used by the shallower soil

**: PAWC and NO3-N for shallower soil only were used in impact assessment and adaptation evaluation 
Table 3 Management information at sowing

\begin{tabular}{|c|c|c|c|}
\hline $\begin{array}{l}\text { NO3-N application } \\
\text { (kg ha-1) }\end{array}$ & $\begin{array}{l}\text { Residue } \\
\text { (kg ha-1) }\end{array}$ & $\begin{array}{l}\text { Plant density } \\
\text { (plants/m²) }\end{array}$ & $\begin{array}{l}\text { Soil water reset } \\
(\mathbf{m m})\end{array}$ \\
\hline 25 & 2000 & 150 & 25 \\
\hline
\end{tabular}


Table 4 Vernalisation and photoperiod sensitivity coefficients

\begin{tabular}{lll}
\hline Levels & vern_sens (V) & photop_sens (P) \\
\hline $\mathbf{0}$ & 1.8 & 2.0 \\
$\mathbf{1}$ & 2.3 & 2.5 \\
$\mathbf{2}$ & $\mathbf{2 . 8}$ & $\mathbf{3 . 0}$ \\
$\mathbf{3}$ & 3.3 & 3.5 \\
$\mathbf{4}$ & 3.8 & 4.0 \\
\hline \multicolumn{2}{l}{ The bold italic figures are the coefficients for wheat cultivar-Chara }
\end{tabular}


Table 5 Current cultivars within the APSIM-Wheat package relevant to South Australia

\begin{tabular}{|c|c|c|c|}
\hline Cultivar Name & vern_sens (V) & photop_sens (P) & Maturity \\
\hline $\begin{array}{l}\text { Annuello, Frame, Yitpi, } \\
\text { Mitre, Yallaroi }\end{array}$ & 1.5 & 3 & Mid maturing \\
\hline Babbler, Baxter & 1.5 & 3.5 & Mid maturing \\
\hline Bellaroi & 2 & 3.5 & Mid maturing \\
\hline H45, Tamaroi, Silverstar & 1.6 & 1.8 & Early-Mid maturing \\
\hline Sunlin, Chara & 2.8 & 3 & Mid-late maturing \\
\hline Kelallac & 2.5 & 4 & Mid-late maturing \\
\hline $\begin{array}{l}\text { Rosella, Lorikeet, } \\
\text { Whistler, Wedgetail }\end{array}$ & 5 & 1 & Winter Wheat \\
\hline
\end{tabular}


Table 6 Changes in median flowering time (days) at Keith

\begin{tabular}{llllll}
\hline & P0 & P1 & P2 & P3 & P4 \\
\hline v0 & -14 & -9 & -2 & 6 & 15 \\
v1 & -11 & -7 & -2 & 6 & 15 \\
v2 & -7 & -4 & 0 & 7 & 15 \\
v3 & -3 & 0 & 3 & 9 & 16 \\
v4 & 2 & 4 & 8 & 13 & 19 \\
\hline
\end{tabular}

hanges were calculated between Chara (v2p2) and synthetic cultivars based on historical climate data 1906-2005 for sowing time 27May. Synthetic cultivars were represented by the combinations of different levels of photoperiod (P) and vernalisation (V) coefficients as given in Table 4. 


\section{Legend}

Figure 1 Usage of historical climate data. Information flow linked by arrow represents direct use of historical climate data in the two ancillary studies. Information flow linked by block arrow represents indirect use of historical climate data.

Figure 2 Distribution of sowing time based on 100-year (1906-2005) historical climate data based on cultivar Chara. Sowing time was quantified by using sowing rules as given by Luo et al., 2005a.

Figure 3 Yield distributions for five levels of NO3-N application rate at sowing time 27 May at Keith

Figure 4 Yield (based on cultivar Chara) distributions under two climate scenarios (baseline and 2080), two levels of plant water available capacity (high and low) and two sowing times (27 May and 13 May). Please note that 13 May sowing is for adaptation evaluation purpose. Baseline wheat yield for this sowing time is not given. H: high PWAC; L: low PAWC; B: baseline; F: future time frame (2080); 147 and 133 are sowing times (Julian day) which correspond to sowing time of 27 May and 13 May respectively. The vertical bars were the distance between the 100th $(0$ th $)$ and the $75^{\text {th }}\left(25^{\text {th }}\right)$ percentile of grain yield.

Figure 5 Yield responses in 2080 to changes in $\mathbf{N}$ application rate and in cultivar choice under high and low PAWC conditions 


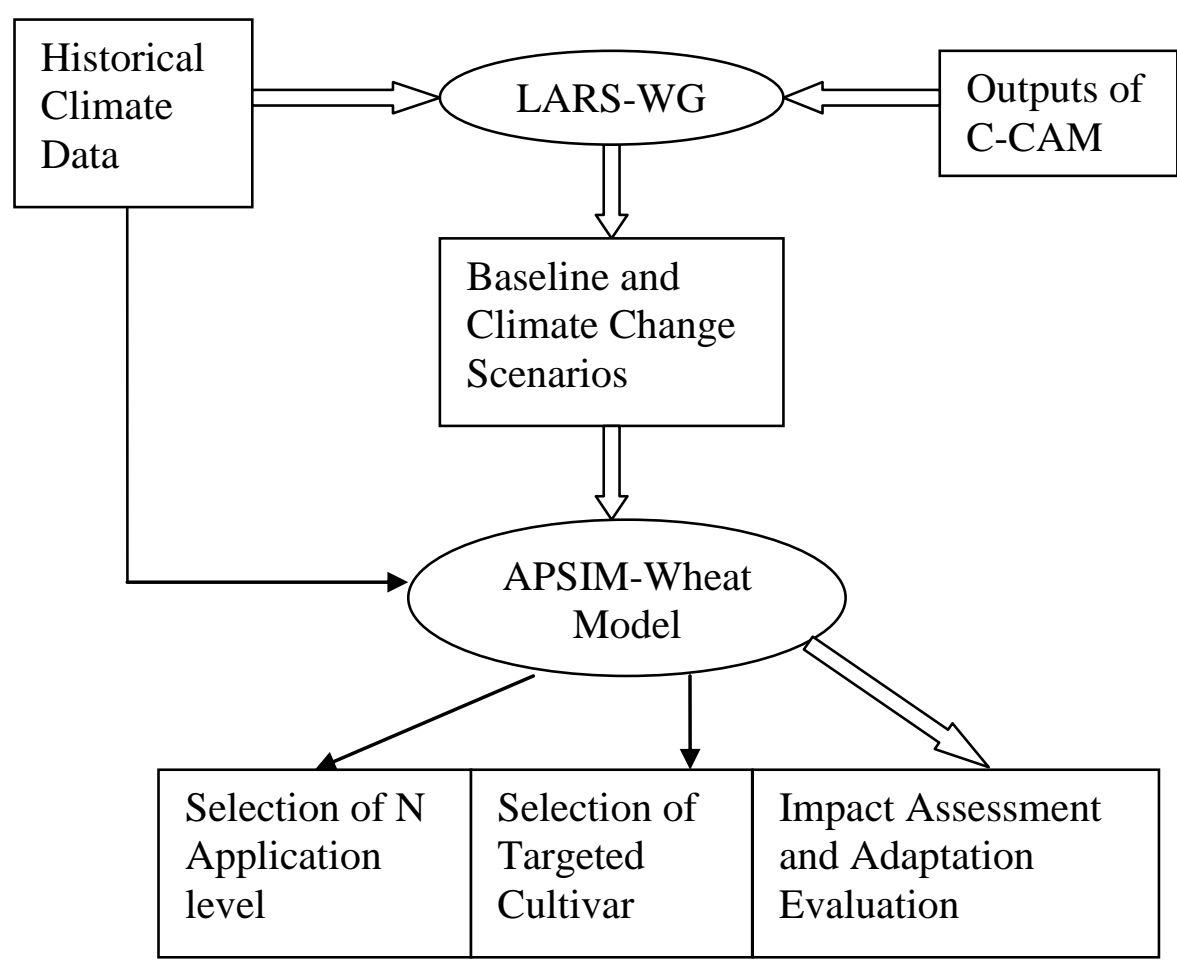




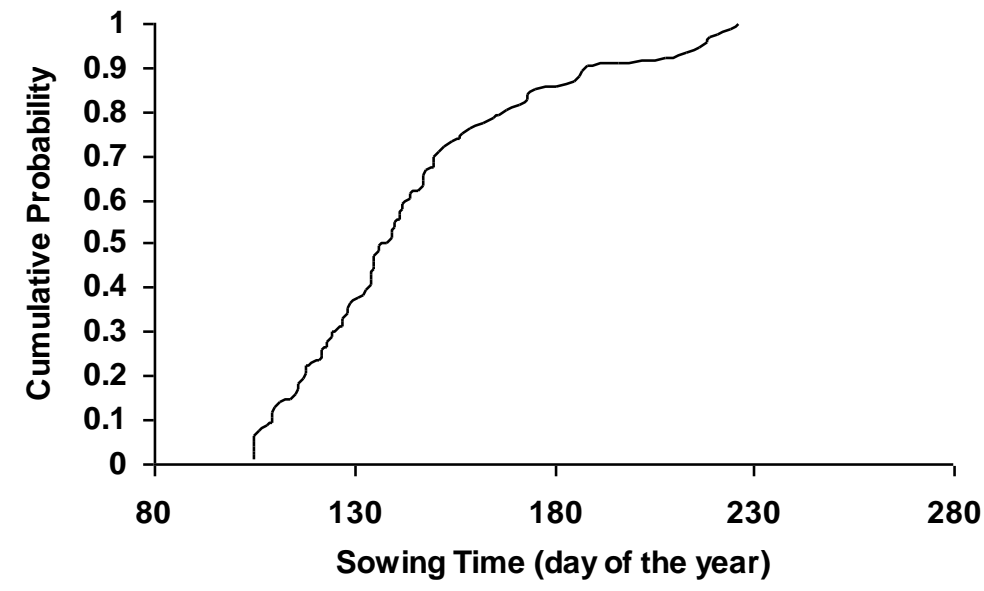


Figure 3

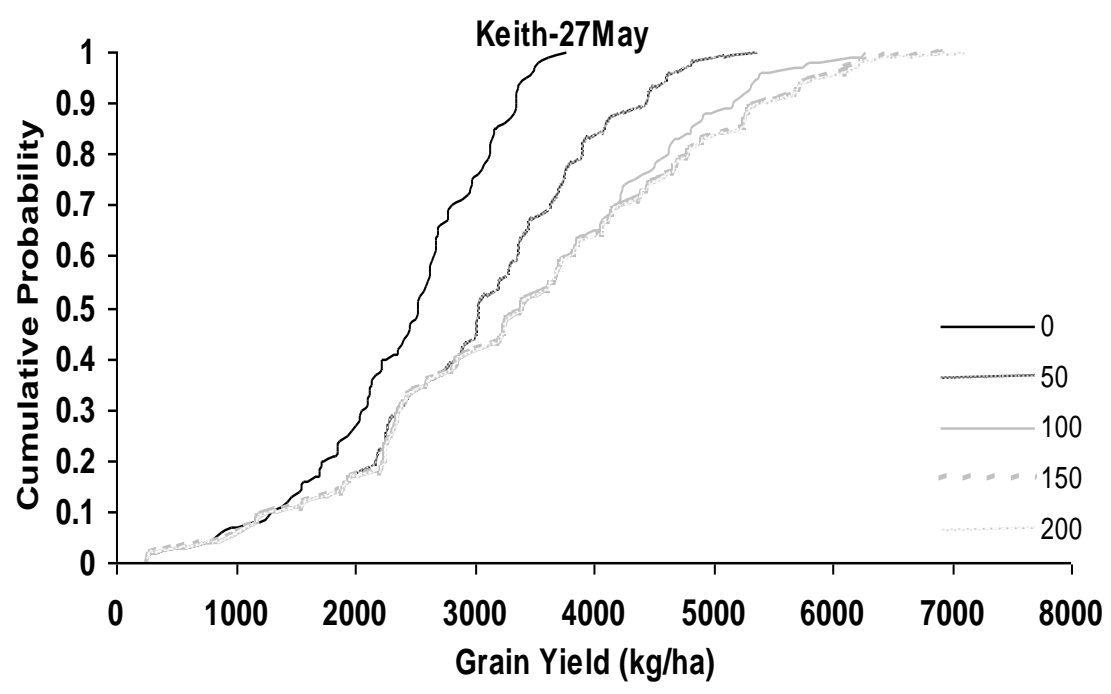




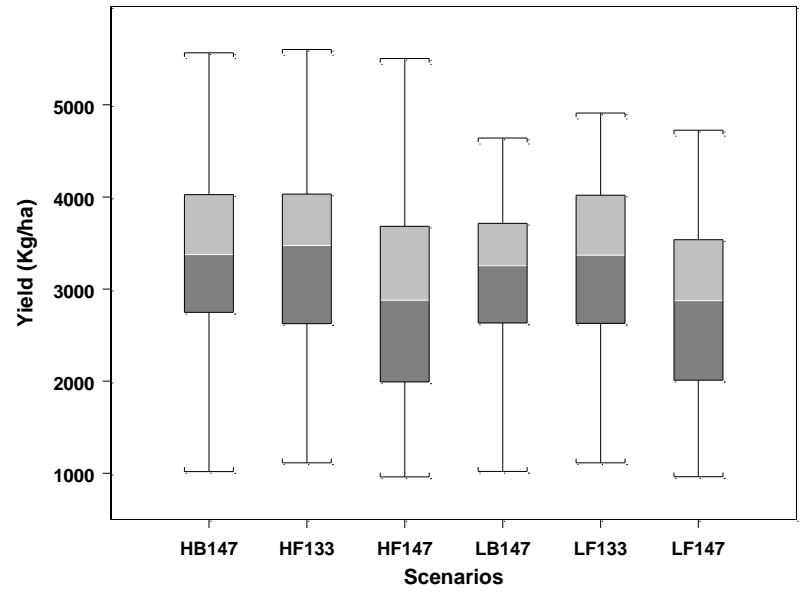



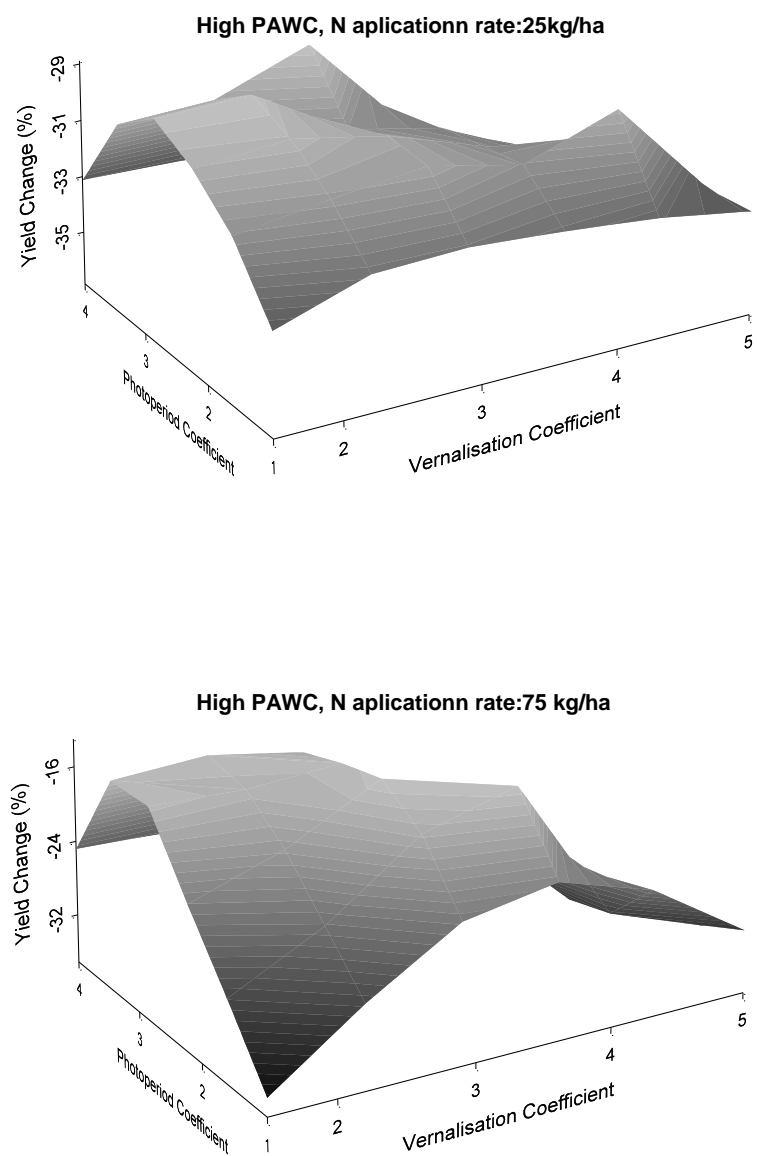

High PAWC, N aplicationn rate:125kg/ha

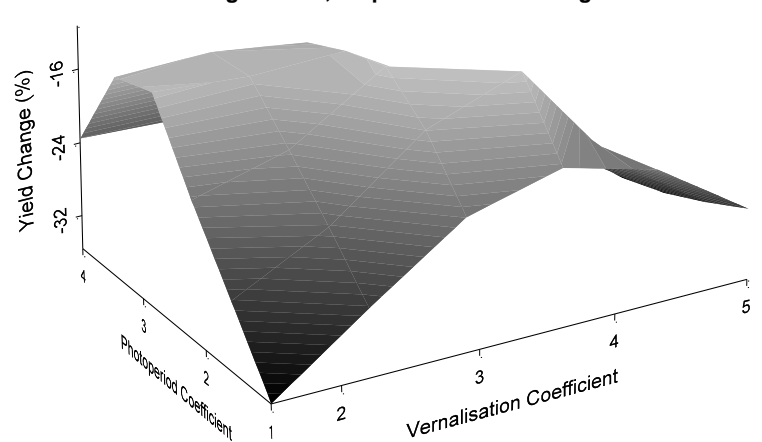




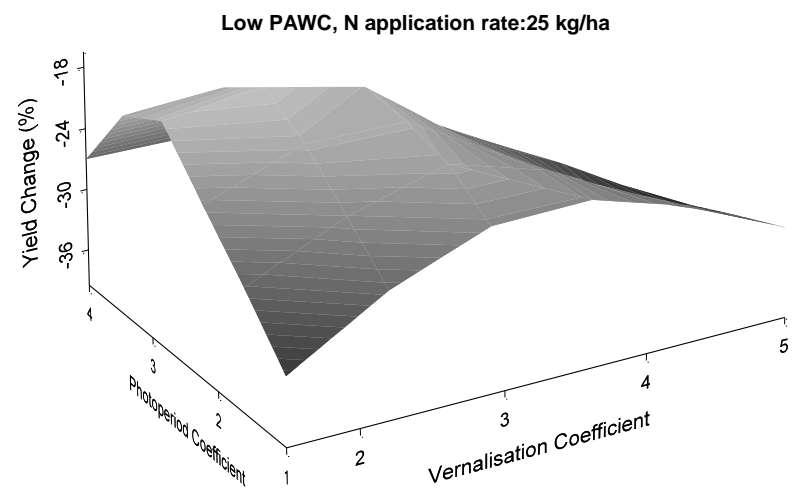

Low PAWC, $\mathrm{N}$ application rate: $75 \mathrm{~kg} / \mathrm{ha}$

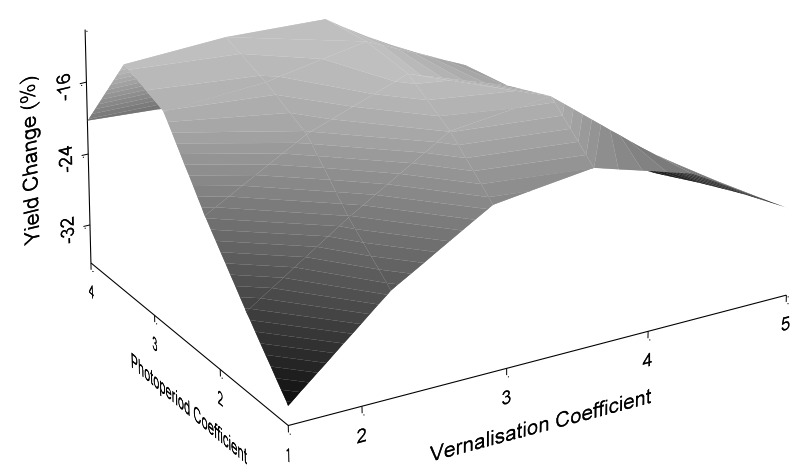

Low PAWC, $\mathrm{N}$ application rate: $125 \mathrm{~kg} / \mathrm{ha}$

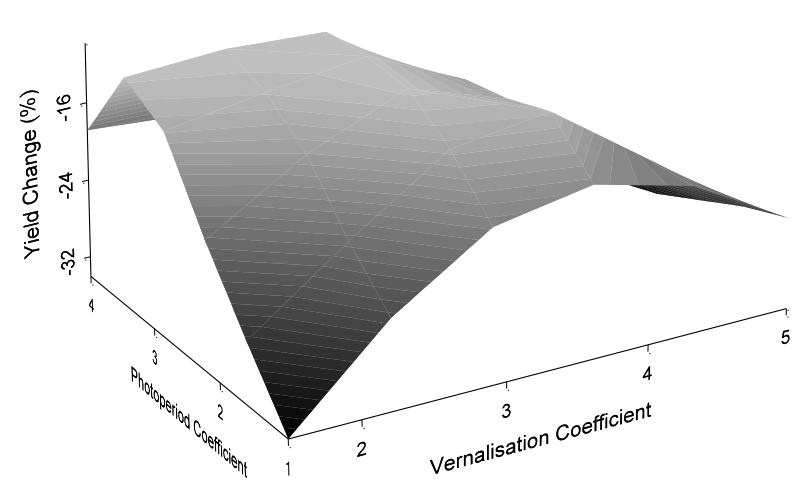

